exclusive for analytical purposes. In our initial analysis we separated out various ethnic groups, but during the peer review and revision process we were asked to present pooled results for our Table 1 and for the final logistic regression. Nevertheless, we did specifically discuss differences between ethnic groups in our Results section. With regard to potential underpowering, we acknowledged small numbers as a limitation of the study and understand that there may have been a lack of power to detect other potential differences.

We believe it is both scientifically and ethically sound to view this study as having the potential to improve the lives of people who have suffered and continue to suffer health disparities.

\section{Wanda M. Wenman}

Department of Pediatrics

University of California, Davis

Davis, Calif.

Michel R. Joffres

Community Health and Epidemiology

Dalhousie University

Halifax, NS

Ivanna V. Tataryn

Department of Obstetrics and

Gynecology

University of Alberta

Edmonton, Alta.

\section{References}

1. Wenman WM, Joffres MR, Tataryn IV, Edmonton Perinatal Infections Group. A prospective cohort study of pregnancy risk factors and birth outcomes in Aboriginal women. CMAf 2004;171(6):585-9.

2. Mohatt GV, Hazel KL, Allen J, Stachelrodt M, Hensel C, Faith R. Unheard Alaska: culturally anchored participatory action research on sobriety with Alaska Natives. Am 7 Community Psychol 2004;22:263-73.

3. Wenman WM, Tataryn IV, Joffres MR, Pearson R, Grace MGA, Albritton WL, et al. Demographic, clinical and microbiological characteristics of maternity patients: a Canadian clinical cohort study. Can F Infect Dis 2002;13(5):311-8.

DOI:10.1503/cmaj.1050006

\section{[Dr. Cass responds:]}

$\mathrm{J}^{2}$ anet Smylie appropriately stresses the need for mutual respect, understanding and partnership if research relating to indigenous communities is to truly benefit those communities. Her argument is supported by our research in the Northern Territory of Australia, which explores the extent of miscommunication in health care delivery and its impact on quality of care. ${ }^{1}$ In that study health care professionals used participatory action methodology to collaborate with Aboriginal patients and community members in planning and conducting the research and then in using the results to improve delivery of services for people with chronic kidney disease.

Smylie also expresses concern about use of the categorization "Aboriginality" in health research, arguing that it has "little grounding in the day-to-day realities of the heterogeneous groups to which it refers." Despite concerns regarding the quality of indigenous identification in health data sets, this categorization can be used to demonstrate inequitable access to care and inequitable health outcomes. ${ }^{2}$ Such data will be required to support efforts to improve health equity.

As outlined in my commentary, ${ }^{3}$ the "indigenous" or "Aboriginal" label needs to be unpacked to determine which specific factors maintain health disparities and which particular characteristics of individual communities should shape policy interventions so that they are both appropriate to local conditions and sustainable.

\section{Alan Cass \\ Director \\ Policy and Practice Division \\ The George Institute for International \\ Health \\ Sydney, Australia \\ References \\ 1. Cass A, Lowell A, Christie M, Snelling PL, Flack M, Marrnganyin B, et al. Sharing the true stories: improving communication between Abo- riginal patients and healthcare workers. Med $\mathcal{f}$ Aust 2002;176(10):466-70. \\ 2. Tonelli M, Hemmelgarn B, Manns B, Py- lypchuk G, Bohm C, Yeates K, et al. Death and renal transplantation among Aboriginal people undergoing dialysis. CMA7 2004;171(6):577-82. \\ 3. Cass A. Health outcomes in Aboriginal popula- tions [editorial]. CMAf 2004;171(6):597-8. \\ DOI:10.1503/cmaj.1050039}

\section{Clinical trials registry}

The requirement of the Interna- 